Proceedings

\title{
Geo-statistical Approaches to Study the Influence of Land Use on Avi- fauna in North Africa.
}

\author{
Hani Amir Aouissi 1,* (D) , Alexandru-Ionuț Petrişor 2,3 (D) , Aissam Gaagai ${ }^{1}{ }^{(\mathbb{D})}$, Mostefa Ababsa ${ }^{1}$ (D) , Feriel Kheira \\ Kebaili 4
}

1 Scientific and Technical Research Center on Arid Regions (CRSTRA), Biskra, 07000, Algeria; aouissi.amir@gmail.com; gaagaiaissam37@gmail.com; mustapha.ababsa@gmail.com

2 Doctoral School of Urban Planning, Ion Mincu University of Architecture and Urbanism, Bucharest, Romania, 010014; alexandru.petrisor@uauim.ro

3 National Institute for Research and Development in Tourism, 50741 Bucharest, Romania

4 Laboratoire de recherche et d'étude en aménagement et urbanisme (LREAU), USTHB Algiers, 16000, Algeria; kebailifer.94@gmail.com

* Correspondence: aouissi.amir@gmail.com Tel.: +213 662387144 (H.A.A)

\begin{abstract}
Land use and cover changes are important to study for their environmental impact on sustainability. In urban environments, an important controversial question addresses the relationship between urbanization-related changes and biodiversity. Birds are ecologically important, and useful for answering this question. This study builds upon the hypothesis according to which avian diversity decreases with urbanization. 4245 samples from 650 sites in Annaba, obtained through the IPA method, were investigated by computing Shannon-Wiener's diversity index and the species richness, mapping, and analyzing. The findings indicate a significant decrease of biodiversity from green spaces to urban areas, confirming our hypothesis. Furthermore, the month of observation, LCUC, and vegetation had a significant influence on the abundance. Moreover, the results fill in a lack of data on the biodiversity of the region.
\end{abstract}

Keywords: geo-statistical approaches; urban ecology; urban planning.

Land use and land cover represent an assembly of natural and anthropogenic factors, and are an essential part of the terrestrial ecosystems [1]. The crucial importance of studying LCUC results from their being part of the "global changes" [2]. Thus, studying LCUC makes an important contribution to the sustainable development debate.

Urbanization, representing an important LCUC driver, is also a major driving force of biodiversity loss and biological homogenization [3], generating a disproportionate share of environmental impacts compared to the total area affected by it [4]. The effects include habitat fragmentation, which in its turn influences species and biogeochemical cycles. Urban sprawl is also the main threat to non-urbanized areas [5].

While the overall influence of fragmentation on the urban ecosystem has been studied from a plethora of perspectives, its direct connection with biodiversity is still debated in the literature. Some authors associate fragmentation with a low biodiversity of small isolated patches. Other authors found out that urban sprawl reduces species richness, but the abundances of some species might peak due to edge effects [6], and even rare and endangered species can be preserved in urbanized habitats [7]. On an intermediate position, some authors consider that urban biodiversity depends on the spatial structure [8], differentiating between species in the city and also highlighting the need for avian biodiversity. More specifically, for birds it is not so important to have continuous green spaces because of their specific movement ways, but according to Angold et al. [9], ensuring the s/by/4.0/) 
diversity of green spaces is more important. For this reason, it is important to phrase land use policies, which account for the need for biodiversity.

Urban ornithology in Algeria remains scarce [10]; information is still incomplete. In the area of Annaba, despite its ecological importance and strategic position, there are too few studies dealing with avian diversity. The most noteworthy urban studies carried out in the area focused only on one species such as the Collared Dove (Streptopelia decaocto) [11] or the Feral Pigeon (Columba livia) [12].

The objective of this study is to study the controversial relationship between biodiversity and urbanization by analyzing avian diversity in Annaba along an urbanization gradient. We hypothesize that the diversity decreases towards the urban environment, along with the reduction of vegetated areas. This study investigates all the avian species encountered during the field sampling.

\section{Materials and Methods}

This work was conducted in the City of Annaba (Algeria) which has become the $3^{\text {rd }}$ largest city in Algeria. It is located between the latitude of $7^{\circ} 42^{\prime}$ and $7^{\circ} 48^{\prime}$ east, and the longitude of $36^{\circ} 50^{\prime}$ and $37^{\circ} 57^{\prime}$ north. The city covers $1412 \mathrm{~km}^{2}$. The method of I.P.A, "indice ponctuel d'abondance" was used for the collection of data. It consists, for an observer, of staying motionless for 10 minutes and recording all visual and audio contacts with birds. Sampling was performed twice by H.A.A on all sites identified cartographically. Data was collected on each site twice a day: early morning and before sunset. In order to avoid overlapping, a minimum distance of $100 \mathrm{~m}$ was maintained between sites.

The study used a novel geo-statistical approach, combining geospatial techniques with statistics. In detail, field observations were mapped, combined with remote sensing data on land cover and use, and spatial analyses were carried out based on the statistical processing of data. Data used in this research comes from field observations and remote sensing data. Field observations were acquired in the period 2017-2018 from 650 sites, classified, following the methodology of Aouissi et al. [13, 14], based on the land cover and use data, as "green space" "intermediate", and "urban". There were 4245 raw observations, each line including the name of species, number of individuals, coordinates of the site, date of observation, type of the site, presence of vegetation (\%), and whether the observation was made during the reproductive season or not. Observations from 2018 did not have influence significantly the avian diversity and were eliminated.

The final data set had 2738 observations, each line containing the site, species, and number of individuals. This data set was used to compute for each site separately two indices of diversity: the species richness is defined as the total number of species per site, and Shannon-Wiener's informational entropy index was computed using Equation 1:

$$
H=\sum_{n}^{i=1}(-1) \times p_{i} \times \ln \left(p_{i}\right)
$$

Where $\mathrm{n}$ is the total number of species, and $p_{i}$ is the share of individuals from species $i$ from the total number of individuals per site.

The choice of the two indices was motivated by their ability to compare the diversity of different sites [15] or of the same site during time [16] and of visualizing distributions in a spatial perspective, when used in conjunction with geo-statistical approaches [17].

Spatial data was derived from satellite imagery, overlaying the distribution of sites with the image to determine the land cover and use for each site. Satellite imagery and geographical data, including the administrative limits, was obtained from the Cartography Department of the National Hydraulic Basins Agency.

The results were analyzed statistically using GLM to find the influence of different factors, including the year and month of collection, vegetation, and whether the observation was made during the reproductive season or not, on the abundance, and determine the relationship between land cover and use and biodiversity, using ANOVA with post- 
hoc comparison tests: Tukey, Bonferroni, and Scheffé. The statistics were computed using 1 Excel 2003 (Microsoft, Spring Valley, CA, USA).

\section{Results}

The analysis of the 4245 observations revealed the presence of 28 bird species. The results of the statistical analysis of the overall data set are presented in Table 1 . The table combines two GLM; the first one, labeled "full model", includes all variables, and the second, labeled "prediction model", only those statistically significant. The first model was overall statistically significant, with $\mathrm{F}=12.83$ and $\mathrm{p}<0.0001$; it had an adjusted $\mathrm{R}^{2}$ of 0.043524 . The second model was overall statistically significant, with $\mathrm{F}=13.71$ and $\mathrm{p}<0.0001$; it had an adjusted $\mathrm{R}^{2}$ of 0.043419 .

Table 1. General Linear Models examining the relationship between the number of individuals from each bird species and variables with a potential influence on it.

\begin{tabular}{|c|c|c|c|c|c|c|c|c|c|}
\hline \multirow[b]{2}{*}{ Variable } & \multicolumn{5}{|c|}{ Full model } & \multicolumn{4}{|c|}{ Prediction model } \\
\hline & DF & $\begin{array}{c}\text { Type } \\
\text { III SS }\end{array}$ & $\begin{array}{c}\text { Mean } \\
\text { Square }\end{array}$ & $\begin{array}{c}F \\
\text { Value }\end{array}$ & $\operatorname{Pr}>$ F DF & $\begin{array}{l}\text { Type } \\
\text { III SS }\end{array}$ & $\begin{array}{l}\text { Mean } \\
\text { Square }\end{array}$ & $\begin{array}{c}\text { F } \\
\text { Value }\end{array}$ & $\operatorname{Pr}>$ F \\
\hline Month & 11 & 1021.8 & 92.9 & 8.6 & $<.000111$ & 1175.1 & 106.8 & 9.9 & $<.0001$ \\
\hline Land cover and use & 2 & 724.5 & 362.2 & 33.6 & $<.00012$ & 727.1 & 363.5 & 33.7 & $<.0001$ \\
\hline Presence of vegetation & 1 & 103.3 & 103.3 & 9.6 & 0.00201 & 102.9 & 102.9 & 9.5 & 0.0020 \\
\hline Reproductive season & 1 & 5.0 & 5.0 & 0.5 & $0.4953-$ & - & - & - & - \\
\hline
\end{tabular}

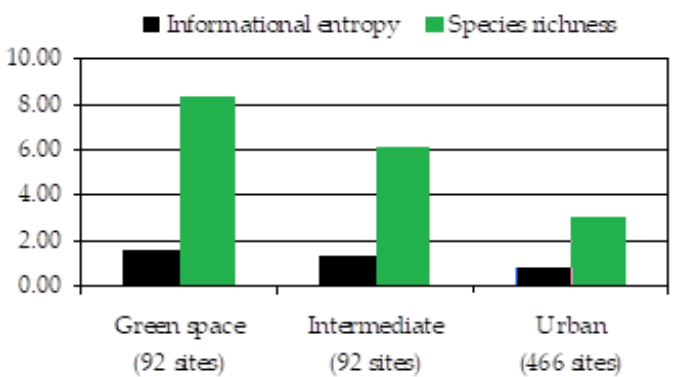

Figure 2. Distribution of Shannon-Wiener's informational entropy index and species richness across the gradient of urbanization in Annaba, Algeria.

More exactly, the results of the Analysis of Variance indicate that there are statistically significant differences between the three types of sites ("green space", "intermediate", and "urban") with respect to the species richness ( F=440.77, p<0.0001) and ShannonWiener's informational entropy index $(\mathrm{F}=177.17, \mathrm{p}<0.0001)$. The results were confirmed by all the three post-hoc tests, which found significant differences between the values of the two indicators among each possible pair of sites.

\section{Discussion}

This study aimed to test the hypothesis according to which the biodiversity in inversely proportional with the degree of urbanization. The statistical analyses confirmed the hypothesis, showing than the biodiversity of green spaces is significantly greater than the one of intermediate and urban sites. These results bring additional evidence to the fact that biodiversity is negatively influenced by urbanization, leaning the balance of the existing controversies in this direction. At the same time, spatial analyses cast a new light on the potential implications, especially in relationship to planning. Finally, the results have a special importance from a methodological perspective, indicating the importance of combining statistical approaches with geo-spatial techniques in order to get a detailed picture of the spatial distribution of biodiversity. 
Our study is one of only few such studies conducted in Northern Africa. Provided that Algeria in general remains very little studied [18,19], and the study region specifically, this study fills in an important gap in the knowledge of the North African avian biodiversity, urban environment in general and the biodiversity related to this type of habitats is often overlooked[20]. In the majority of cases, studies were carried out only outside of the urbanized areas until recently. The idea that cities are regarded as deserts from an ornithological point of view tends to be abandoned over time.

Even if our results show a decrease in bird diversity along the urbanization gradient, they also show a high richness of green spaces within urban areas, and the presence of the same species found outside the city. A high concentration of diversity and abundance in environments with significant vegetation should be noted, testifying for the importance of green spaces in urban environments.

Funding: This research received no external funding.

Conflicts of Interest: The authors declare no conflict of interest. 